\title{
Efficacy and indications of transradial and transfemoral approaches for peripheral artery stent implantation
}

\author{
PENG CHEN, HUIJIE LI, CHUNYU ZENG, YUQIANG FANG, WEIBIN SHI, \\ XIAOQUN ZHANG and CHENGMING YANG \\ Department of Cardiology, Daping Hospital, Third Military Medical University, Chongqing 400042, P.R. China
}

Received February 1, 2016; Accepted February 10, 2017

DOI: 10.3892/etm.2017.4307

\begin{abstract}
The transradial approach (TRA) has become an attractive alternative to the transfemoral approach (TFA) in percutaneous coronary intervention. To date, however, these two approaches have not been systematically compared in various percutaneous peripheral artery interventions (PPAIs). In the present study 258 patients with peripheral artery disease that underwent PPAI via the TRA $(n=75)$ or the TFA $(n=183)$ were analyzed. Clinical factors and outcomes in these two groups were compared. The puncture time was significantly longer $(\mathrm{P}<0.05)$ and the prevalence of artery vasospasm significantly higher $(\mathrm{P}<0.05)$ in patients who underwent PPAI via the TRA rather than via the TFA. However, the complication rate was significantly lower $(\mathrm{P}<0.05)$ and the artery compression time $(\mathrm{P}<0.05)$ and time bedridden $(\mathrm{P}<0.05)$ were significantly shorter via the TRA than via the TFA. These results suggest that PPAI via the TRA was associated with a lower complication rate, and shorter artery compression time and bedridden time than PPAI via the TFA. The TRA may be preferable for bilateral vertebral artery stenosis, whereas the TFA may be preferable for interventional treatment of carotid and subclavian artery stenosis. Therefore, the catheter length, artery support and push force should be comprehensively considered before choosing the TRA or TFA in the interventional treatment of renal artery stenosis.
\end{abstract}

\section{Introduction}

With the development of interventional devices and techniques, percutaneous peripheral artery intervention (PPAI) has been considered an effective replacement for traditional open surgery (1-3). The routine puncture approach for percutaneous

Correspondence to: Dr Chengming Yang, Department of Cardiology, Daping Hospital, Third Military Medical University, 10 Changjiang Street, Chongqing 400042, P.R. China

E-mail: yangchmi@163.com

Key words: transradial approach, transfemoral approach, peripheral artery disease, stent implantation, percutaneous peripheral artery intervention coronary intervention (PCI) has been via the femoral artery, but recently, the transradial approach (TRA) has become an attractive alternative to the transfemoral approach (TFA) for PCI (4-6). The two approaches have similar success rates (4-6), with bleeding complications reduced $>70 \%$ by the TRA (7). In a previous study, we have shown that the procedure time was short and the rate of complications was low when angiography was performed using a single $5 \mathrm{~F}$ multipurpose catheter via the TRA, with no effect on the angiography success rate (8).

Inserting stents of large diameter into peripheral arteries is difficult when these arteries are smaller in diameter $(9,10)$. Arteries in the upper extremities are less able to support catheters and are more difficult to manipulate than the femoral artery, resulting in a longer surgery time for the former. The majority of physicians therefore prefer to perform PPAI via the TFA rather than the TRA $(11,12)$. However, use of the TFA also has several disadvantages, including the patient being bedridden for a longer time and a higher incidence of bleeding $(13,14)$. Moreover, it may be very difficult or even impossible to insert a catheter via the TFA due to a seriously tortuous aortic arch and/or peripheral artery disease (PAD), making the TRA an alternative approach (5-8). To date, however, no study has systematically compared these two approaches in various PPAIs. Therefore, 258 PAD patients who underwent PPAI via the TRA or TFA were analyzed in the present study and their outcomes and characteristics were compared.

\section{Materials and methods}

Study setting. The present study involved a total of 258 patients with PAD, diagnosed according to the ACC/AHA 2005 Practice Guidelines (15), with supra-arch or renal artery stenosis who underwent PPAI via the TRA or TFA at Daping Hospital of the Third Military Medical University (Chongqing, China) between January 2007 and March 2012. Patients were included if they had PAD and underwent supra-arch or renal artery stent implantation. Patients unable to undergo stent implantation due to coagulation disorders, cancer or inflammation were excluded. The present study was approved by the Ethics Committee of Daping Hospital of the Third Military Medical University and all subjects provided written informed consent. 
Preoperative preparation. Routine preparations prior to stent implantation included monitoring of the radial artery pulse, auscultation of the subclavian and axillary artery regions, Allen tests, color Doppler examination of the arteries of the upper limbs, skin shaving of the inguinal areas and upper extremities and skin tests with novocaine (Southwest Pharmaceutical Co., Ltd., Chongqing, China) and antibiotics (Sichuan Changzheng Pharmaceutical Co., Ltd., Leshan, China). All patients were administered aspirin (300 mg; Bayer HealthCare, Beijing, China) and clopidogrel (300 mg; Sanofi S.A., Paris, France) the day prior to the procedure.

Angiography. Selective angiographies of the coronary, supra-aortic and renal arteries were performed via TRA. The supra-aortic artery consists of the left and right vertebral, carotid and subclavian arteries and the angiography method has been previously described (8).

Selection of a guiding catheter. For the TFA, an MPA (8F) guiding catheter (Johnson \& Johnson, New Brunswick, NJ, USA) was used for the left and right vertebral, carotid and subclavian arteries, with a special guiding catheter (Johnson \& Johnson) for the renal arteries. For TRA, a J6FL (3.5 or 4.0F) guiding catheter (Medtronic, Inc., Minneapolis, Minnesota, USA) through an upper extremity artery was used for the left vertebral artery and a JR6F (3.5 or 4.0F) guiding catheter (Medtronic, Inc.) through an upper extremity artery was used for the right vertebral artery. Furthermore, a J8FL (4.0F) or J8FR (4.0F) guiding catheter (Medtronic, Inc.) through an upper extremity artery was used for the carotid and subclavian arteries and a JR6F (3.5 or 4.0F) guiding catheter (Medtronic, Inc.) through an upper extremity artery was used for the left and right renal arteries.

Stent implantation. Depending on the result of angiography, the guiding catheter was placed into the opening of lesion-affected vessels and extended to the lesions along the guidewire. Arteries with severe stenosis, tortuous angulation or calcification were balloon predilatated. A distal protection device (FilterWire EZ; Boston Scientific Corp., Natick, MA, USA) was placed at the petrous segment of the internal carotid artery before stent implantation into the carotid artery. Stents placed in the carotid and subclavian arteries were self-expandable, whereas stents placed in the vertebral and renal arteries were balloon expandable. Furthermore, the stents were not released until suitable locations were reached. If the lesions were eccentric or with spiral tears, fluoroscopy was performed at several positions to confirm that stent locations were optimal. Following successful angiopoiesis, angiography was performed again. The guiding catheter and the sheath were removed immediately after surgery, with the puncture site covered by a pressure bandage.

Post-operative management. Vital signs of patients were monitored. The conditions around the puncture site were monitored to determine whether there was bleeding, exudation or hematoma. When necessary, angiography was performed again. Pressure bandages placed on radial artery puncture sites were removed $4 \mathrm{~h}$ after PCI, after which patients were not required to stay in bed. Pressure bandages placed on femoral artery puncture sites were removed $24 \mathrm{~h}$ after PCI, during which time patients had to remain supine in bed with the hip joint in position to restrict access to the puncture. All patients were prescribed aspirin (100 mg/day) and clopidogrel (75 mg/day) for one year post-operatively.

Statistical analyses. Data are expressed as the mean \pm standard deviation. Student's t-test was used to compare the differences between groups and the $\chi^{2}$ test was used to compare categorical variables. A 2 -tailed value of $\mathrm{P}<0.05$ was considered statistically significant. Furthermore, all analyses were performed using SPSS statistical software (version 16.0; SPSS, Inc., Chicago, IL, USA).

\section{Results}

Baseline characteristics of patients. Patient characteristics at baseline are shown in Table I. The 258 patients consisted of 168 males and 90 females, ranging in age between 48 and 80 years (mean age, 64.0 \pm 9.6 years). Routine preoperative examination showed that all patients had a good radial artery pulse, there was no murmur in the subclavian and axillary artery areas and hemodynamics were stable. All 258 patients had been diagnosed with coronary heart disease, with 185 also having hypertension, 150 also having type 2 diabetes mellitus and 116 also having posterior circulation ischemia. Furthermore, the 258 patients were implanted with 300 stents, including 42 patients implanted with 2 stents each.

Procedure time, time bedridden and complications of stent placement via the TRA or TFA. Of the 258 patients, 75 (29.1\%) underwent stent placement via the TRA and $183(70.9 \%)$ via the TFA. The puncture time was significantly longer $(\mathrm{P}<0.05)$ and arteries had a higher prevalence of vasospasm $(\mathrm{P}<0.05)$ in the TRA than in the TFA. However, the complication rate was significantly lower $(\mathrm{P}<0.05)$, and artery compression $(\mathrm{P}<0.05)$ and bedridden $(\mathrm{P}<0.05)$ times were significantly shorter for the TRA than for the TFA (Table II).

Selection of an approach for placement of peripheral vascular stents. The approach selections for the 300 stents implanted into the 258 patients are shown in Table III.

Of the 99 stents placed in bilateral vertebral arteries (examples of which are shown in Fig. 1), 78 (78.8\%) were placed via the TRA and $21(21.2 \%)$ via the TFA. Of the 21 patients who underwent the TFA (Fig. 2), 3 did so due to difficulties inserting a guiding catheter into the left vertebral artery, resulting from severe circuitry of the right subclavian artery and aortic arch. The other 18 patients had lesions of other arteries, making it more convenient to insert stents into these arterial lesions via the TFA rather than via the TRA.

Of the 66 stents placed in bilateral renal arteries (Fig. 3), $27(40.9 \%)$ were inserted via the TRA and $39(59.1 \%)$ via the TFA. TFA was used if the catheter could not reach the ideal position or could not provide enough supporting force due to the patient height being $>180 \mathrm{~cm}(12 / 27,44.4 \%$; Fig. 4); if it was very difficult to insert the guiding catheter into the target artery (even the descending aorta) due to severe circuitry of the right subclavian artery or aortic arch (6/27, 22.2\%; Fig. 5); or if 
Table I. Baseline characteristics of patients $(n=258)$.

\begin{tabular}{lc}
\hline Characteristics & Values \\
\hline Age, years & $64.0 \pm 9.6$ \\
Gender, n (\%) & \\
Male & $168(65.1)$ \\
Female & $90(34.9)$ \\
Clinical diagnosis, $(\%)$ & \\
Stable angina & $59(22.9)$ \\
Unstable angina & $191(74.0)$ \\
Old myocardial infarction & $8(3.1)$ \\
Complications, $\mathrm{n}(\%)$ & \\
Hypertension & $185(71.7)$ \\
Diabetes & $150(58.1)$ \\
Posterior circulation ischemia & $116(45.0)$ \\
Medications, $\mathrm{n}(\%)$ & \\
Aspirin & $240(93.0)$ \\
Clopidogrel & $41(15.9)$ \\
Statins & $96(37.2)$ \\
Stents, n (\%) & \\
One & $216(83.7)$ \\
Two & $42(16.3)$ \\
\hline
\end{tabular}

Table II. Procedure time, time bedridden and complications in patients who underwent stent placement.

\begin{tabular}{lcc}
\hline & $\begin{array}{c}\text { Radial } \\
\text { artery } \\
\text { approach } \\
(\mathrm{n}=75)\end{array}$ & $\begin{array}{c}\text { Femoral } \\
\text { artery } \\
\text { approach } \\
(\mathrm{n}=183)\end{array}$ \\
Characteristics & $66.0 \pm 7.9$ & $68.2 \pm 11.1$ \\
\hline Age, years & & \\
Gender, $\mathrm{n}(\%)$ & 58 & 110 \\
Male & 17 & 73 \\
Female & $14.2 \pm 6.9^{\mathrm{a}}$ & $3.8 \pm 2.2$ \\
Time from puncture to & $2(2.7)^{\mathrm{a}}$ & $16(8.7)$ \\
successful catheterization, min & $0^{\mathrm{a}}$ & $9(4.9)$ \\
Bleeding and hematoma, $\mathrm{n}(\%)$ & $0^{\mathrm{a}}$ & $7(3.8)$ \\
Arteriovenous fistula, $\mathrm{n}(\%)$ & $7(9.3)^{\mathrm{a}}$ & 0 \\
Pseudoaneurysm, $\mathrm{n}(\%)$ & $0^{\mathrm{a}}$ & $20(10.9)$ \\
Vasospasm, $\mathrm{n}(\%)$ & $0^{\mathrm{a}}$ & $6(3.3)$ \\
Vasovagal reaction, $\mathrm{n}(\%)$ & $4.0 \pm 1.7^{\mathrm{a}}$ & $18.2 \pm 4.7$ \\
Use of stitching instrument, $\mathrm{n}(\%)$ & $2.7 \pm 1.5^{\mathrm{a}}$ & $13.6 \pm 5.6$ \\
Artery compression time, min & & \\
Bedridden time, $\mathrm{h}$ & &
\end{tabular}

${ }^{\mathrm{a}} \mathrm{P}<0.05$ vs. transfemoral approach.

patients had lesions in other arteries, making it more convenient to insert stents via the TFA than via the TRA $(9 / 27,33.3 \%)$.

Of the 134 stents inserted into the bilateral carotid and subclavian arteries (Fig. 6), 3 (2.2\%) were inserted via the
Table III. Selection of an approach for peripheral vascular stenting.

\begin{tabular}{lcc}
\hline Artery & $\begin{array}{c}\text { Transradial artery } \\
\text { approach }(\mathrm{n}=109)\end{array}$ & $\begin{array}{c}\text { Transfemoral artery } \\
\text { approach }(\mathrm{n}=191)\end{array}$ \\
\hline Left vertebral & 30 & 18 \\
Right vertebral & 48 & 3 \\
Left subclavian & 0 & 33 \\
Right subclavian & 3 & 3 \\
Left carotid & 0 & 45 \\
Right carotid & 0 & 50 \\
Renal & 27 & 39 \\
Mesenteric & 1 & 0 \\
\hline
\end{tabular}

TRA and $131(97.8 \%)$ via the TFA. Since the maximum size of arterial sheath that can pass through the upper extremity artery is 7F, the TFA was preferred for these arteries. Since it is very difficult to place guiding catheters into arterial lesions due to severe lower extremity artery malformation or subclavian artery angulation, 9 patients underwent procedures via the TRA (Fig. 7).

Of note, 1 patient had recurrent abdominal pain with no abdominal findings on computed tomography (CT), gastroscopy or colonoscopy. Furthermore, a CT scan of the mesenteric artery showed severe stenosis in the opening of the superior mesenteric artery. One stent was placed in the mesenteric artery of this patient via the TRA (Fig. 8).

\section{Discussion}

Since the femoral artery is easy to puncture, it is possible to pass a large arterial sheath or peripheral arterial stent delivery system through it, and the intervention path is straight and relatively short. Furthermore, the TFA has been the most frequent access route in PCI for a long time (4-6,16). However, the TFA prolongs the duration of confinement to bed, requires a longer hospital stay and has a high incidence of bleeding complications $(13,14)$, suggesting the need for an alternative approach.

The first transradial coronary angiography was performed in 1989 (17) and the first successful coronary artery stent implantation via a transradial artery was performed in 1993 (18). Furthermore, the success rates of the TRA and TFA have been found to be similar (4-6), with the TRA reducing major bleeding and ischemic events $(13,14)$. In a previous study, it was found that angiography using a single $5 \mathrm{~F}$ multipurpose catheter via the TRA shortened the procedure time and reduced the complication rate without affecting the angiography success rate (8). Over the past 20 years, the TRA has become one of the most chosen approaches in percutaneous coronary angiography and PCI. To date, to the best of our knowledge, no study has yet systematically compared these two approaches in various PPAIs.

The majority of physicians prefer to perform PPAI via the TFA rather than via the TRA, regarding the TRA as an alternative only when it is very difficult or impossible to insert a catheter via the TFA due to a seriously tortuous aortic arch 

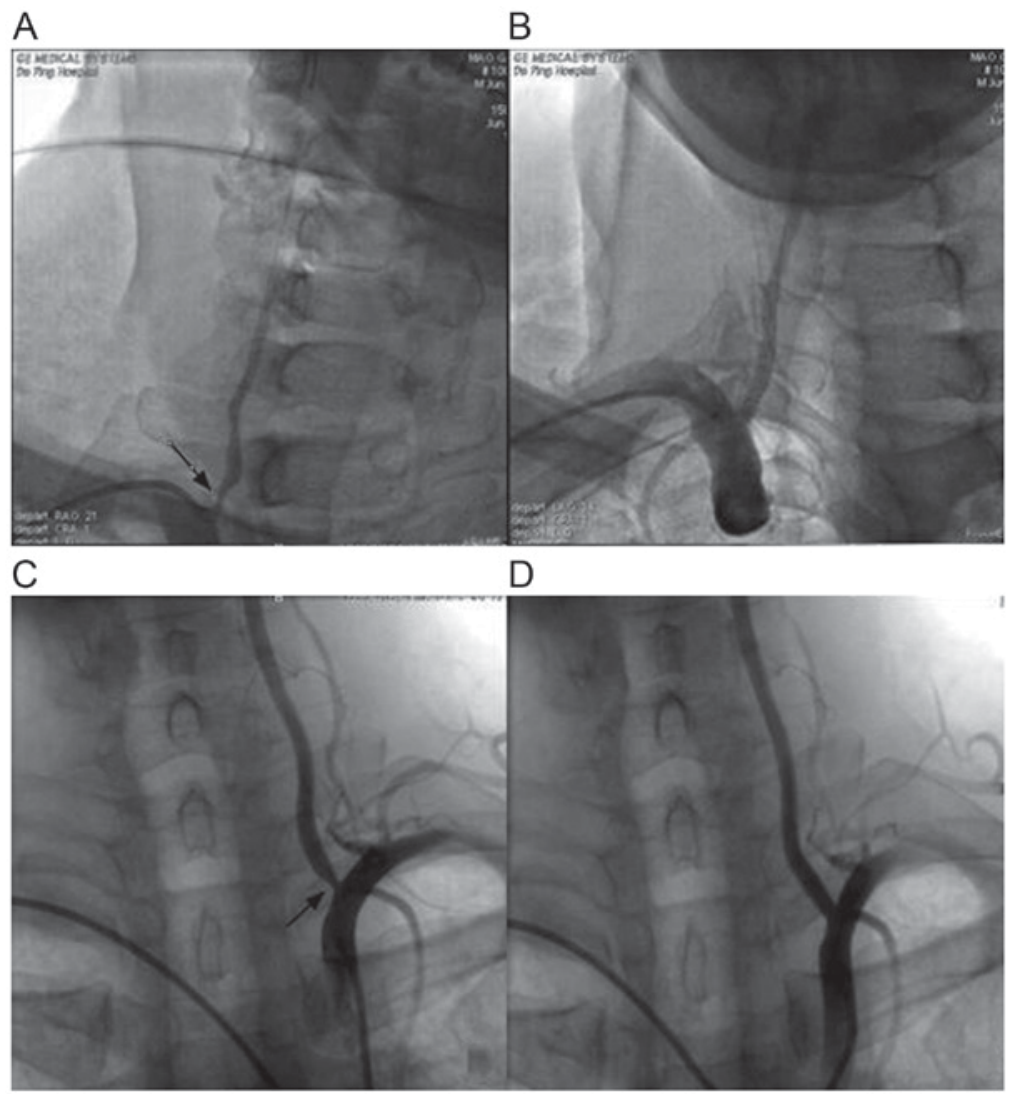

Figure 1. Vertebral artery stent placement via the transradial approach in a male patient with dizziness for 5 years. (A) Stenoses of the right vertebral artery opening and (B) absence of stenoses following stent placement via the transradial approach. (C) Stenoses of the left vertebral artery opening and (D) absence of stenoses after stent placement via the transradial approach. The arrows indicate stenosis.

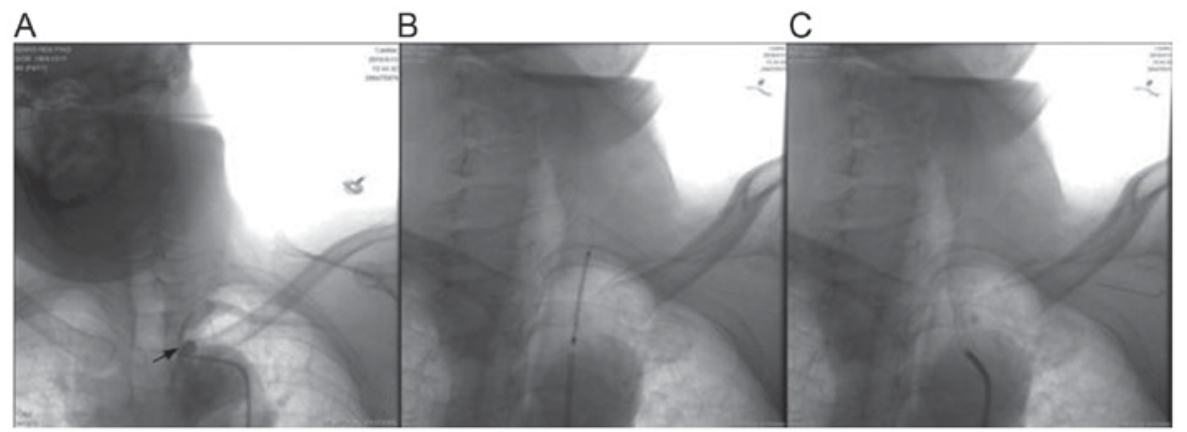

Figure 2. Subclavian artery stent placement via the transfemoral approach. (A) Subclavian artery stenosis, (B) stent placement via the transfemoral approach and $(C)$ stent expansion. The arrow indicates stenosis.

and/or peripheral vascular disease (5-8). In the present study, a total of 258 patients with PAD who underwent PPAI, 75 via the TRA and 183 via the TFA were analyzed. The results indicated that the time from puncture to successful catheterization was longer for the TRA, possibly because arteries in the upper extremities are less able to provide catheter support and the operation was more difficult $(9,10)$.

By contrast, it was found that the complication rate was lower and the artery compression and bedridden times shorter for the TRA than for the TFA. A previous study demonstrated that radial access for PCI reduced major bleeding by $73 \%$ and hospital stay by 0.4 days compared with femoral access (7). One coronary study showed that the total procedural time was significantly longer with the TRA than the TFA (18.1 vs.
$15.0 \mathrm{~min}$ ), although the fluoroscopy time did not differ (19). Another study of lower extremity intervention found no difference in the total fluoroscopy time for the TRA and TFA (30.4 vs. $26.6 \mathrm{~min}$ ) (11). Furthermore, a previously published study and our previous study even demonstrated a significant reduction in the total procedural times using the TRA for coronary catheterizations $(7,8)$. However, further in-depth analysis is required to explain these contradictory results.

Since the TFA and TRA each have both advantages and disadvantages, the present study summarizes our findings, and we tentatively suggest how to choose the correct approach for use in PPAI.

Angiography via the TRA was routinely performed in order to determine the arterial path and particularly the relationship 


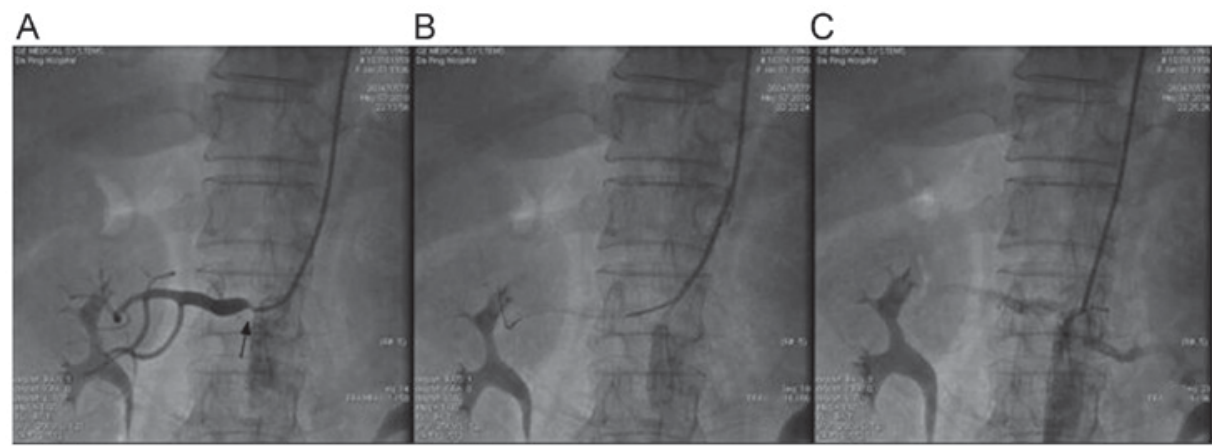

Figure 3. Renal artery stent placement via the transradial approach in a male patient with hypertension for 3 years. (A) Severe renal artery stenoses, (B) stent placement and (C) stent expansion. The arrow indicates stenosis.

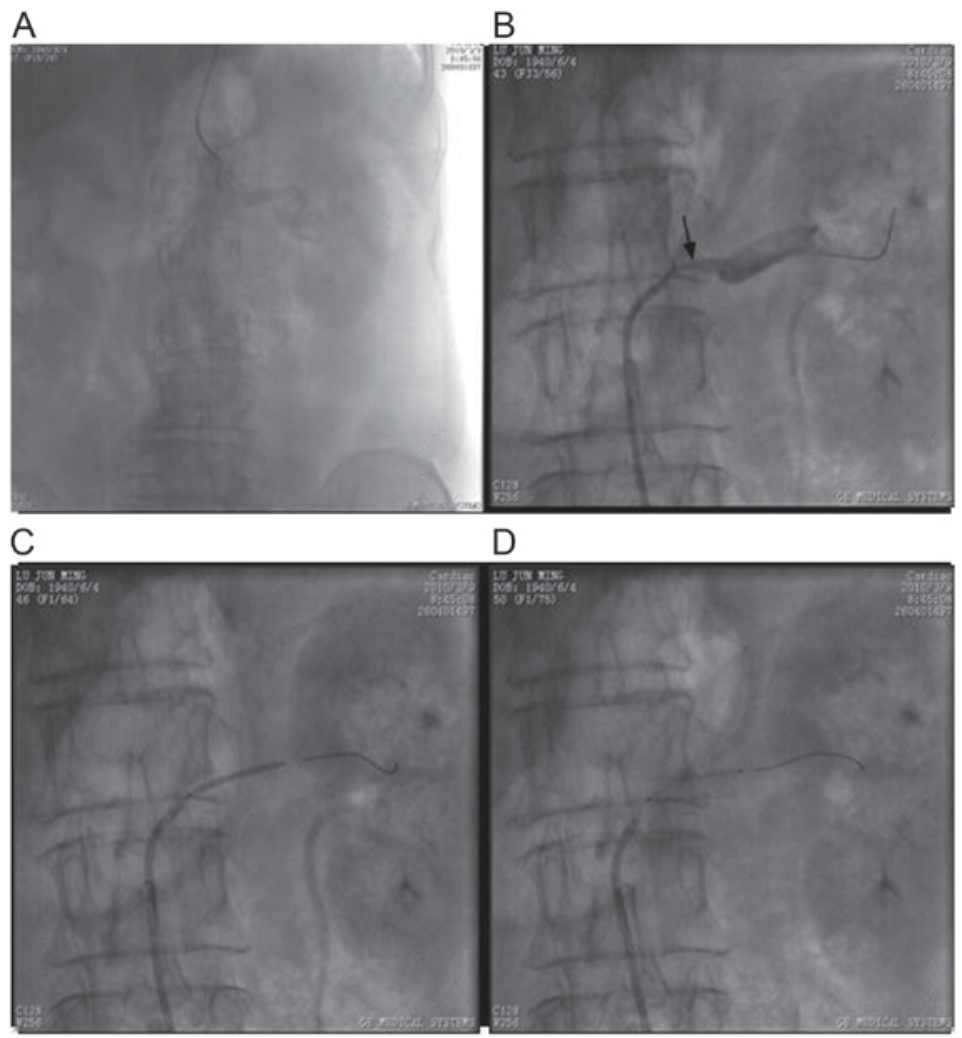

Figure 4. Renal artery stent placement via the transfemoral approach in a male patient with hypertension for 5 years and height $>180 \mathrm{~cm}$. (A) Inability of a $120-\mathrm{cm}$ catheter to reach the ideal position via the transradial approach. (B) Treatment of severe renal artery stenoses via the transfemoral approach, (C) stent placement and (D) stent expansion. The arrow indicates stenosis.

A

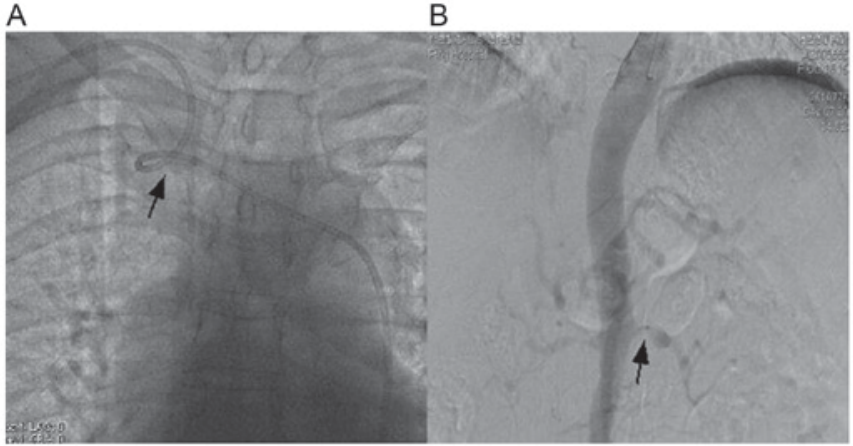

Figure 5. Renal artery stent placement via the transfemoral approach. (A) Severe circuitry of the right subclavian artery and (B) failure to insert the guiding catheter into the opening of the renal artery via the transradia approach, as indicated by the respective arrows. and angulation between the aortic arch and right brachiocephalic trunk, which is the key to determining the optimal approach. A $6-8 \mathrm{~F}$ arterial sheath is able to pass through radial arteries. We previously found that a single $5 \mathrm{~F}$ multipurpose catheter via the TRA had no effect on the coronary angiography success rate (8), a finding confirmed in the present study on peripheral artery angiography. Although treatment with nitroglycerin $(100 \mu \mathrm{g})$ and lidocaine $(200 \mu \mathrm{g})$ could reduce the incidence of radial artery spasm (20,21), use of a single multipurpose catheter may also avoid radial artery spasm $(8,22)$. Since the path from the right radial to the renal artery is long and extends across the aortic arch, the length of a multipurpose catheter is sometimes insufficient $(8,23)$. When this occurred, a $125 \mathrm{~mm}$ long single bend angiography catheter was selected or a left radial artery approach was used for selective renal arteriography. 


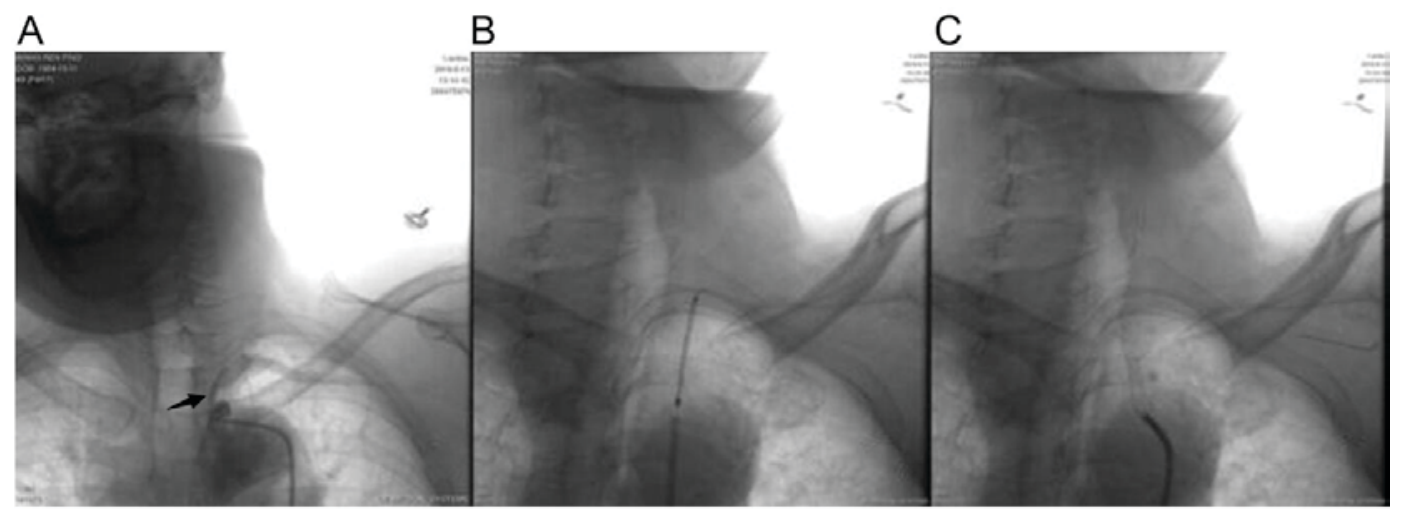

Figure 6. Carotid artery stent placement via the transfemoral approach in a male patient with dizziness for 3 years. (A) Angiography via the transradial approach showing stenosis of the left subclavian artery and the renal artery, (B) stent placement and (C) stent expansion. The arrow indicates stenosis.

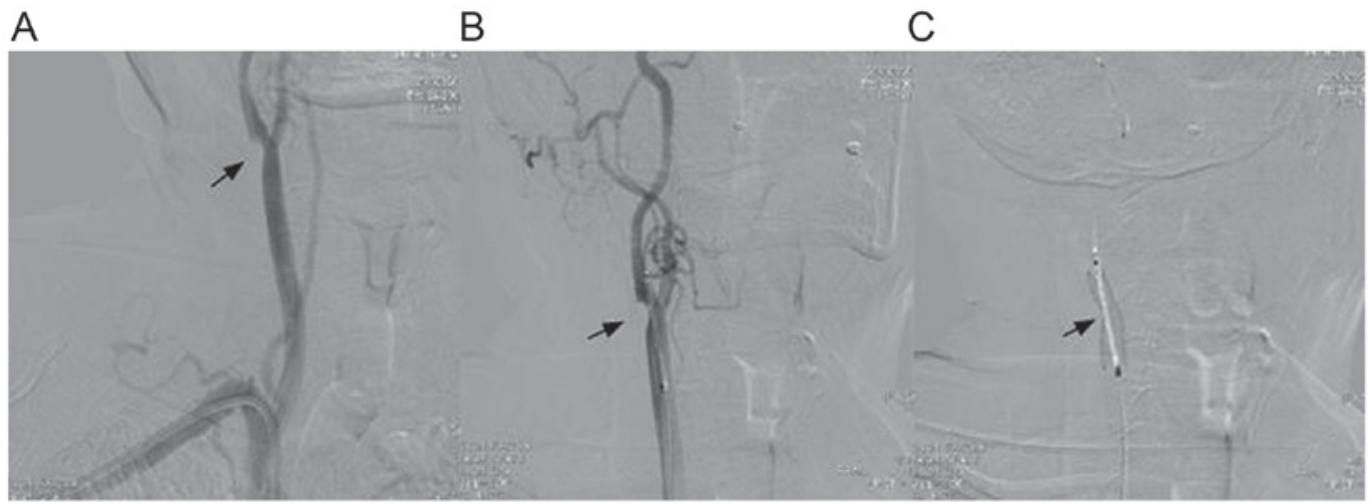

Figure 7. Carotid artery stent placement via the transradial approach in a male patient. (A) Angiography via the transradial approach, showing stenosis of the right carotid artery, (B) stent placement and (C) stent expansion, as indicated by the respective arrows.

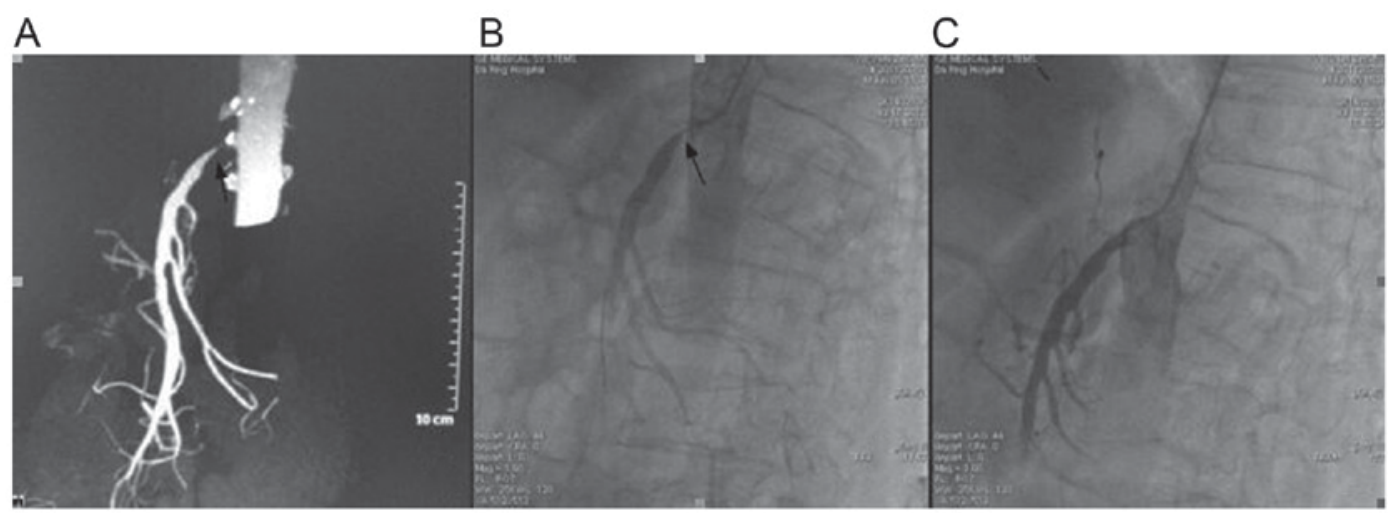

Figure 8. Stent placement into the superior mesenteric artery via the transradial approach. (A) A computed tomography scan of the superior mesenteric artery, (B) digital subtraction angiography via the transradial approach, showing severe stenosis at the opening of the superior mesenteric artery and (C) stent placement and expansion. The arrow indicates stenosis.

The path between the right radial and right vertebral artery is shorter, with less vascular variation, making it more easily accessible and able to provide enough support and push force for a catheter. Therefore, in the present study as well as in other studies, a right radial artery approach was selected $(8,24)$. In the present study, the catheter was unable to reach the left vertebral artery via the right TRA only in three patients. A left radial artery approach could therefore be selected to complete the interventional therapy. The subclavian artery is smaller in diameter than the carotid and vertebral arteries, enabling the use of a stent with a diameter 3.5-4.0 $\mathrm{mm}(12,25)$, and the TRA can satisfy these requirements.

The renal artery is usually opened upwards, making the catheter more easily accessible via the TRA than the TFA. Since the diameter of the renal artery is $4-7 \mathrm{~mm}$, a guiding catheter with a small diameter can transfer the stents $(26,27)$. In our opinion, renal artery stent implantation via the right TRA should be performed only in patients $<165 \mathrm{~cm}$ in height and 
with vessels along the interventional path that are not severely bent. For the left TRA, we recommend that the maximum patient height is $170 \mathrm{~cm}$. This approach would not provide sufficient support and push force for patients with severely tortuous supra-aortic arch arteries, even if the guiding catheter is transferred to the opening of the renal artery with difficulty. In such patients, the TFA is preferable for the interventional treatment of renal artery stenosis.

Although the catheter can easily reach head and neck artery lesions via the TRA, the stents used in the carotid and subclavian artery interventions are larger in diameter $(28,29)$. Thus, it is difficult to insert $8 \mathrm{~F}$ arterial sheaths through radial arteries. In the present study, only nine patients underwent carotid and subclavian artery interventions via TRA. If insertion of a guiding catheter into the lesion artery was difficult due to a severely tortuous aortic arch or serious peripheral vascular disease, then the TRA was preferable for interventional treatment in patients with stenosis of the carotid and subclavian arteries. These patients, however, should be assessed preoperatively by a color Doppler examination to confirm that the diameter of the upper limb artery is sufficient.

In the present preliminary study, limitations, including small sample size, the study being performed at a single center and incomplete enrollment (if patients had not received the required interventions to be included in the study), introduced a certain selection bias. In addition, a comparison of different catheters in PPAIs may interfere with procedure-related complications. Radial and femoral arteries differ in diameter, requiring different catheters to be used for the TRA and TFA approaches, which reflects real-world practice. However, further well-designed prospective studies are required to better address these issues.

In conclusion, PPAI via the TRA is associated with a lower complication rate and shorter artery compression and bedridden times than PPAI via the TFA. Based on our previous experience, it was found that bilateral vertebral artery stenosis was the best indication to perform interventional therapy via TRA. Furthermore, the TFA is preferable for the interventional treatment of carotid and subclavian artery stenosis. Catheter length, artery support and push force should be comprehensively evaluated to determine whether the TRA or TFA is optimal for the interventional treatment of renal artery stenosis. However, the present study has some limitations and further well-designed prospective investigations are required.

\section{Acknowledgements}

The authors thank all of their colleagues in the Departments of Cardiology and Radiology at Daping Hospital (Chongqing, China).

\section{References}

1. Mateo RB, O'Hara PJ, Hertzer NR, Mascha EJ, Beven EG and Krajewski LP: Elective surgical treatment of symptomatic chronic mesenteric occlusive disease: Early results and late outcomes. J Vasc Surg 29: 821-832, 1999.

2. Antoniou GA, Chalmers N, Georgiadis GS, Lazarides MK, Antoniou SA, Serracino-Inglott F, Smyth JV and Murray D: A meta-analysis of endovascular versus surgical reconstruction of femoropopliteal arterial disease. J Vasc Surg 57: 242-253, 2013.
3. West AM, Anderson JD, Epstein FH, Meyer CH, Hagspiel KD, Berr SS, Harthun NL, Weltman AL, Annex BH and Kramer CM: Percutaneous intervention in peripheral artery disease improves calf muscle phosphocreatine recovery kinetics: A pilot study. Vasc Med 17: 3-9, 2012.

4. Agostoni P, Biondi-Zoccai GG, de Benedictis ML, Rigattieri S, Turri M, Anselmi M, Vassanelli C, Zardini P, Louvard Y and Hamon M: Radial versus femoral approach for percutaneous coronary diagnostic and interventional procedures; Systematic overview and meta-analysis of randomized trials. J Am Coll Cardiol 44: 349-356, 2004.

5. Rathore S, Hakeem A, Pauriah M, Roberts E, Beaumont A and Morris JL: A comparison of the transradial and the transfemoral approach in chronic total occlusion percutaneous coronary intervention. Catheter Cardiovasc Interv 73: 883-887, 2009.

6. Romagnoli E, Biondi-Zoccai G, Sciahbasi A, Politi L, Rigattieri S, Pendenza G, Summaria F, Patrizi R, Borghi A, Di Russo C, et al: Radial versus femoral randomized investigation in ST-segment elevation acute coronary syndrome: The RIFLE-STEACS (Radial Versus Femoral Randomized Investigation in ST-Elevation Acute Coronary Syndrome) study. J Am Coll Cardiol 60: 2481-2489, 2012.

7. Carrillo X, Mauri J, Fernandez-Nofrerias E, Rodriguez-Leor O and Bayes-Genis A: Safety and efficacy of transradial access in coronary angiography: 8-year experience. J Invasive Cardiol 24: 346-351, 2012.

8. Fang Y, Yang C, Wang X, Zhou L, Wang H and Zeng C: Feasibility and application of single $5 \mathrm{~F}$ multipurpose catheter in coronary and peripheral angiography via a transradial approach. Int J Cardiol 151: 182-186, 2011.

9. He GW and Yang CQ: Characteristics of adrenoceptors in the human radial artery: Clinical implications. J Thorac Cardiovasc Surg 115: 1136-1141, 1998.

10. Li L, Zeng ZY, Zhong JM, Wu XH, Zeng SY, Tang EW, Chen W and Sun YH: Features and variations of a radial artery approach in southern Chinese populations and their clinical significance in percutaneous coronary intervention. Chin Med J (Engl) 126: 1046-1052, 2013.

11. Korabathina R, Yadav SS, Coppola JT and Staniloae CS: Transradial approach to lower extremity interventions. Vasc Health Risk Manag 6: 503-509, 2010

12. Yu J, Korabathina R, Coppola J and Staniloae C: Transradial approach to subclavian artery stenting. J Invasive Cardiol 22: 204-206, 2010.

13. Rao SV, Ou FS, Wang TY, Roe MT, Brindis R, Rumsfeld JS and Peterson ED: Trends in the prevalence and outcomes of radial and femoral approaches to percutaneous coronary intervention: A report from the National Cardiovascular Data Registry. JACC Cardiovasc Interv 1: 379-386, 2008.

14. Nathan S and Rao SV: Radial versus femoral access for percutaneous coronary intervention: Implications for vascular complications and bleeding. Curr Cardiol Rep 14: 502-509, 2012.

15. Hirsch AT, Haskal ZJ, Hertzer NR, Bakal CW, Creager MA, Halperin JL, Hiratzka LF, Murphy WR, Olin JW, Puschett JB, et al: ACC/AHA 2005 Practice Guidelines for the management of patients with peripheral arterial disease (lower extremity, renal, mesenteric and abdominal aortic): A collaborative report from the American association for vascular surgery/society for vascular surgery, society for cardiovascular angiography and interventions, society for vascular medicine and biology, society of interventional radiology and the ACC/AHA task force on practice guidelines (Writing Committee to develop guidelines for the management of patients with peripheral arterial disease): Endorsed by the American association of cardiovascular and pulmonary rehabilitation; National heart, lung and blood institute; society for vascular nursing; transAtlantic inter-society consensus; and vascular disease foundation. Circulation 113: e463-e654, 2006.

16. Esente P, Giambartolomei A, Simons AJ, Levy C and Caputo RP: Overcoming vascular anatomic challenges to cardiac catheterization by the radial artery approach: Specific techniques to improve success. Catheter Cardiovasc Interv 56: 207-211, 2002.

17. Campeau L: Percutaneous radial artery approach for coronary angiography. Cathet Cardiovasc Diagn 16: 3-7, 1989.

18. Kiemeneij F and Laarman GJ: Percutaneous transradial artery approach for coronary stent implantation. Cathet Cardiovasc Diagn 30: 173-178, 1993.

19. Achenbach S, Ropers D, Kallert L, Turan N, Krähner R, Wolf T, Garlichs C, Flachskampf F, Daniel WG and Ludwig J: Transradial versus transfemoral approach for coronary angiography and intervention in patients above 75 years of age. Catheter Cardiovasc Interv 72: 629-635, 2008. 
20. Dharma S, Shah S, Radadiya R, Vyas C, Pancholy S and Patel T: Nitroglycerin plus diltiazem versus nitroglycerin alone for spasm prophylaxis with transradial approach. J Invasive Cardiol 24: 122-125, 2012.

21. Kristić I and Lukenda J: Radial artery spasm during transradial coronary procedures. J Invasive Cardiol 23: 527-531, 2011.

22. Kim SM, Kim DK, Kim DI, Kim DS, Joo SJ and Lee JW: Novel diagnostic catheter specifically designed for both coronary arteries via the right transradial approach. A prospective, randomized trial of Tiger II vs. Judkins catheters. Int J Cardiovasc Imaging 22: 295-303, 2006.

23. Maddury J, Kaushik M, Madhavapeddi A, Babu S, Kumar N, Varma JL and Alla V: Feasibility and safety of elective transradial coronary intervention in Asian females. J Invasive Cardiol 23: 95-99, 2011.

24. Arsanjani R, Echeverri J and Movahed MR: Successful coil embolization of pericardiacophrenic artery perforation occurring during transradial cardiac catheterization via right radial artery. J Invasive Cardiol 24: 671-674, 2012.

25. Walker C: Will the transradial approach become the preferred approach in subclavian artery stenting? J Invasive Cardiol 22: 207-208, 2010 .
26. Scheinert D, Bräunlich S, Nonnast-Daniel B, Schroeder M, Schmidt A, Biamino G, Daniel WG and Ludwig J: Transradial approach for renal artery stenting. Catheter Cardiovasc Interv 54: 442-447, 2001

27. Luo JF, Wang HY, Huang WH, Liu Y, Li G, Zhou YL and Chen JY: Transradial artery intervention: An alternative approach for renal artery stent implantation? Chin Med J (Engl) 125: 3340-3343, 2012

28. Etxegoien N, Rhyne D, Kedev S, Sachar R and Mann T: The transradial approach for carotid artery stenting. Catheter Cardiovasc Interv 80: 1081-1087, 2012.

29. Fang HY, Chung SY, Sun CK, Youssef AA, Bhasin A, Tsai TH, Yang $\mathrm{CH}$, Chen CJ, Hussein H, Wu CJ and Yip HK: Transradial and transbrachial arterial approach for simultaneous carotid angiographic examination and stenting using catheter looping and retrograde engagement technique. Ann Vasc Surg 24: 670-679, 2010. 